\title{
Influence on Effectiveness of Early Treatment with Anti-TNF Therapy in Rheumatoid Arthritis
}

\author{
Vicente Escudero-Vilaplana ${ }^{1,3}$, Esther Ramírez-Herraiz ${ }^{2}$, Nicolás Trovato-López ${ }^{1,3}$, Estefanía Alañón-Plaza ${ }^{2}$, María José \\ Bellini $^{1,3}$, Ana Herranz-Alonso ${ }^{1,3}$, José María Bellón-Cano ${ }^{3}$, Alberto Morell-Baladrón ${ }^{2}$, María Sanjurjo-Sáez ${ }^{1,3}$ \\ ${ }^{1}$ Pharmacy Department, Gregorio Marañón University General Hospital, Madrid, Spain. \\ ${ }^{2}$ Pharmacy Department, La Princesa University Hospital, Madrid, Spain. \\ ${ }^{3}$ Institute for Health Research, Gregorio Marañón University General Hospital, Madrid, Spain.
}

Received, April 3, 2012; Revised, April 10, 2012; Accepted, May 15, 2012; Published, May 16, 2012.

\begin{abstract}
Purpose. To evaluate the association between starting early treatment with anti-TNF and effectiveness as well as the possibility of applying therapeutic spacing in daily practice in patients with rheumatoid arthritis (RA). Methods. Observational, retrospective study conducted in two universitary hospitals in Spain. RA patients who received the first anti-TNF (adalimumab: ADA, etanercept: ETN or infliximab: IFX) during the study period (October 2006-2010) were included. Demographic data, time since diagnosis, disease activity (DAS28-ESR) and anti-TNF dosage were analyzed. Therapeutic objective was defined as DAS28<2.6. Also the response related to criteria of the European League Against Rheumatism (EULAR) was evaluated. Therapeutic spacing was defined as the use of a lower dose or a higher interval according to label doses. The main endpoint was to assess the association between the effectiveness and the moment when the anti-TNF therapy begins. The secondary target was to evaluate the association between RA activity at the beginning of treatment with anti-TNF and dose used. Results. 82 patients were included. The prescription profile was: ADA (48.8\%), ETN (31.7\%) and IFX (19.5\%). $71.4 \%$ of patients treated with anti-TNF during the first year since diagnosis, $57.1 \%$ of those who started after $1-5$ years and $30.6 \%$ of patients who started after 5 years were in remission when the study ended. De-escalation strategy was performed in $25.6 \%$ of patients: ETN (38.5\%), ADA (20.0\%) and IFX (18.8\%). The patients treated with a higher dose according to label doses were: IFX (81\%), ADA, $(12.5 \%)$ and ETN (7.7\%). Conclusions. Results suggest that early treatment with anti-TNF can achieve a higher percentage of remissions. Therapeutic spacing is established as a strategy that improves the efficiency in those patients in remission, being the ETN the anti-TNF most susceptible for spacing, although a relation between the early beginning with anti-TNF and the used dose was not found.
\end{abstract}

This article is open to POST-PUBLICATION REVIEW. Registered readers (see "For Readers") may comment by clicking on ABSTRACT on the issue's contents page.

\section{INTRODUCTION}

Rheumatoid Arthritis (RA) is a chronic autoimmune disease characterized by inflammation and deterioration of the joints, which can produce a loss of functionality, reduces quality of life and enhances morbimortality $(1,2)$. Its prevalence is $0.5-1 \%$ (3), and it has a high social and economic impact. It is estimated that at 10 years from the beginning of the disease, more than $50 \%$ of patients will suffer a serious disability, and after 15 years just $40 \%$ will be able to work (4). Early diagnosis of RA is fundamental for its management. Most patients will have suffered important radiologic damage in the first two years of the disease, and during this period the structural damage advances more rapidly $(5,6)$. Therefore, the earlier the treatment starts, the higher the probability for managing the inflammatory process and reducing structural damage (7).

The objective of treatment is to achieve complete remission (8). Just for prolonged evolution patients, a low activity state will be considered as target. Treatment allows pain control and prevents damage to articulations and the loss of functionality. It is recommended to start with disease-modifying antirheumatic drugs (DMARDs) as soon as the diagnostic has been established. Normally, treatment begins with methotrexate (MTX). However, in patients with high activity RA, in which a rapid progression can be expected, a combination of MTX and a biologic agent like an anti-TNF is used (9).

\footnotetext{
Corresponding Author: Vicente Escudero-Vilaplana; Pharmacy Department, Gregorio Marañón University General Hospital. Doctor Esquerdo 46, 28007 Madrid, Spain; Email: vescudero.hgugm@salud.madrid.org
} 
The use of biologic therapy (BT) in combination with DMARDs is more effective than using one or various DMARDs; maintaining remission for longer periods, with the possibility of increasing in dosage inteval or withdrawal of BT $(10,11)$. The spacing strategy reduces the number of administrations and therefore the cost associated to the drug.

Our objective was to evaluate the association between the early beginning treatment with antiTNF and the effectiveness and possibility of applying a therapeutic spacing in daily practice in patients with RA. These results will allow for a better understanding and management of RA, since this is one of the first studies whit these goals.

\section{METHODS}

An observational, retrospective and multicenter (two university hospitals) study was carried out. Patients included were adults diagnosed with RA by the Rheumatology Department who were treated with the first anti-TNF between October 2006 and October 2010. Patients who had an exposition to the drug lower than 6 months, receiving another biologic drug or participating in other clinical trials were excluded.

The studied anti-TNFs were: adalimumab (ADA), etanercept (ETN) and infliximab (IFX). The recorded variables were: demographics (age, gender and weight); date of RA diagnosis; previous treatment with MTX and its higher dose; which anti-TNF was used (type, dose, starting and ending dates of the treatment and if the treatment was suspended: date and reason); and the first and the last Disease Activity Score (DAS28) for each anti-TNF.

The efficacy variable was DAS28. Remission of the disease was considered if DAS28 <2.6. Also the response according to criteria of the European League Against Rheumatism (EULAR) was evaluated, collected in Table 1, which takes into account both the degree of reduction of DAS28 as the final absolute value (12).

The principal target was to evaluate the association between the effectiveness and the moment when the anti-TNF therapy began. This initial state was defined according to the first DAS28 and the time between RA diagnosis and the beginning of treatment with anti-TNF.

The secondary target was to evaluate the association between RA activity at the beginning of treatment with anti-TNF and the dose used, to assess if the spacing strategy depends on RA activity at the beginning of the BT. The therapeutic spacing was defined as the use of a lower dose or a higher interval according to label doses, randomly established by specialist's criteria and the patient's consent.

\section{STATISTICAL ANALYSIS}

Results have been shown with the mean and the standard deviation for normal variables and with the median and the percentiles for variables with a non-normal distribution. Kruskal-Wallis test was used for differences between non parametric variables; while differences between categorical variables were evaluated by Pearson's $\chi^{2}$ or Fisher's Exact. Correlation between categorical variables was performed by $\chi^{2}$ test and $\chi^{2}$ test of lineal tendency for ordinal variables. Spearman Rho test was used for the correlation between non parametric variables.

The statistical analysis was performed by the statistical program SPSS 18.0. $\mathrm{P}<0.05$ was considered as significant.

\section{RESULTS}

82 patients were included. The prescription profile was: ADA (48.8\%), ETN (31.7\%) and IFX $(19.5 \%)$. The basal characteristics were recorded in table 2 , where the only statistically significant differences were found in gender of IFX patients compared to ADA and ETN.

\begin{tabular}{llll}
\hline \multicolumn{2}{l}{ Table 1. EULAR response (DAS28). } & \\
\hline \multirow{2}{*}{ Final DAS28 } & Decrease of the DAS28 regard to the basal value. & $>0.6$ \\
& $>1.2$ & $0.6-1.2$ & No response \\
\hline$<3.2$ & Good response & Moderate response & No response \\
$3.2-5.1$ & Moderate response & Moderate response & No response \\
$>5.1$ & Moderate response & No response & \\
\hline
\end{tabular}


Effectiveness data are recorded in table 3, where the only differences were found between ADA and IFX in patients with "moderate" and "none" EULAR response.

Relation between the early beginning of antiTNF therapy and its effectiveness (DAS28)

Influence on the effectiveness of the time between diagnosis and beginning $B T$ :

The time between diagnosis and the first antiTNF and final DAS28 ( $r=0.300, p=0.011)$ and the time between diagnosis and RA final activity $(\mathrm{r}=0.355, \mathrm{p}=0.002)$ showed a positive correlation.

$71.4 \%$ of patients treated with anti-TNF during the first year since diagnosis, $57.1 \%$ of those who started after $1-5$ years and $30.6 \%$ of the ones who started after 5 years were in remission when the study ended.
There was also correlation between the time since the diagnosis and the EULAR response $(\mathrm{r}=0.353, \mathrm{p}=0.003)$ (Table 4).

\section{Influence of initial DAS28 on effectiveness:}

There was a positive correlation between the initial and final DAS28 $(r=0.343, p=0.002)$ and between the initial and final RA activity $(\mathrm{r}=0.245, \mathrm{p}=0.026)$.

$63.6 \%$ of patients treated with the first antiTNF with an initial DAS28 $<3.2,51.4 \%$ of the ones that started with a DAS28: 3.2-5.1 and $27.8 \%$ with an initial DAS28 $>5.1$ were in remission at the end of the study.

Remission percentages, at the end of the study, according to initial RA activity and time since diagnosis starting BT are shown in table 5 .

\begin{tabular}{|c|c|c|c|c|}
\hline \multicolumn{5}{|c|}{$\mathrm{ADA}(\mathrm{n}=40)$} \\
\hline \multicolumn{2}{|l|}{ Age (years) } & $57.7(12.8)$ & $52.3(16.0)$ & $59.6(12.6)$ \\
\hline \multicolumn{2}{|l|}{ Gender (\% women) } & 77.5 & 73.1 & 100.0 \\
\hline \multicolumn{2}{|c|}{ Time since RA diagnosis (years) } & $4.4(2.0,8.2)$ & $6.7(1.3,14.1)$ & $7.2(3.9,15.8)$ \\
\hline \multicolumn{2}{|c|}{$\begin{array}{l}\text { Time with anti-TNF (years) } \\
\text { Initial DAS } 28\end{array}$} & $1.8(0.8,2.9)$ & $2.6(1.5,3.4)$ & $1.7(0.9,2.2)$ \\
\hline \multicolumn{2}{|l|}{ Initial DAS28 } & $4.8(1.2)$ & $4.9(1.5)$ & $4.4(1.4)$ \\
\hline & DAS $28<2.6$ & 5.0 & 7.7 & 6.3 \\
\hline RA initial activity (\% & DAS28: $2.6-3.2$ & 5.0 & 7.7 & 12.5 \\
\hline \multirow{2}{*}{ patients) } & DAS28: 3.2-5.1 & 47.5 & 30.8 & 50.0 \\
\hline & DAS28 $>5.1$ & 42.5 & 53.8 & 31.3 \\
\hline \multicolumn{2}{|c|}{ Previous treatment with MTX (\% patients) } & 95.0 & 88.8 & 100.0 \\
\hline \multicolumn{2}{|c|}{ Maximun dose of MTX (mg) } & 14.9 & 15.1 & 15.0 \\
\hline
\end{tabular}

\begin{tabular}{|c|c|c|c|c|}
\hline \multicolumn{2}{|l|}{ Final DAS28 } & $\begin{array}{l}\text { ADA }(n=40) \\
2.8(1.3)\end{array}$ & $\begin{array}{l}\operatorname{ETN}(n=26) \\
3.0(1.5)\end{array}$ & $\begin{array}{l}\operatorname{IFX}(\mathrm{n}=16) \\
3.5(2.0)\end{array}$ \\
\hline \multirow{4}{*}{$\begin{array}{l}\text { RA final activity } \\
\text { (\% patients) }\end{array}$} & DAS $28<2.6$ & 50.0 & 34.6 & 37.5 \\
\hline & DAS28: $2.6-3.2$ & 15.0 & 26.9 & 18.8 \\
\hline & DAS28: $3.2-5.1$ & 30.0 & 30.8 & 18.8 \\
\hline & DAS2 $28>5.1$ & 7.7 & 5.0 & 25.0 \\
\hline \multicolumn{2}{|c|}{ Reduction of the DAS28 } & $2.0(1.2)$ & $1.8(2.0)$ & $0.9(2.0)$ \\
\hline Response of the & Good response & 52.5 & 50.0 & 43.8 \\
\hline EULAR & Moderate response & 40.0 & 26.9 & 6.3 \\
\hline (\% patients) & No response & 7.5 & 23.1 & 50.0 \\
\hline \multicolumn{2}{|c|}{$\begin{array}{l}\text { Suspension of the anti-TNF ( } \% \\
\text { patients) }\end{array}$} & 5.0 & 11.5 & 18.8 \\
\hline \multicolumn{2}{|c|}{ Reason for suspension ( $\%$ reason) } & 100 adverse effect & $\begin{array}{l}66.6 \text { therapeutic failure, } \\
33.3 \text { adverse effect }\end{array}$ & $\begin{array}{l}66.6 \text { therapeutic failure, } \\
33.3 \text { adverse effect }\end{array}$ \\
\hline
\end{tabular}




\begin{tabular}{lccc}
\hline \multicolumn{1}{l}{ Table 4. Relation of the time between diagnosis and beginning of anti-TNF therapy and the EULAR response. } \\
\hline & $\begin{array}{l}\text { Time since the } \\
\text { diagnosis }<1 \text { year } \\
(\mathrm{n}=7)\end{array}$ & $\begin{array}{l}\text { Time since the } \\
\text { diagnosis 1-5 years } \\
(\mathrm{n}=28)\end{array}$ & $\begin{array}{l}\text { Time since the } \\
\text { diagnosis }>5 \text { years } \\
(\mathrm{n}=36)\end{array}$ \\
\hline Good response (\% patients) $(\mathrm{n}=37)$ & $85.7 \%$ & $64.3 \%$ & $36.1 \%$ \\
Moderate response (\% patients) $(\mathrm{n}=22)$ & $14.3 \%$ & $25.0 \%$ & $38.9 \%$ \\
No response (\% patients) $(\mathrm{n}=12)$ & $0.0 \%$ & $10.7 \%$ & $25.0 \%$ \\
\hline
\end{tabular}

\begin{tabular}{|c|c|c|c|c|}
\hline & $\begin{array}{l}\text { Time after diagnosis } \\
<1 \text { year }(\mathrm{n}=7)\end{array}$ & $\begin{array}{l}\text { Time after } \\
(\mathrm{n}=28)\end{array}$ & diagnosis $1-5$ years & $\begin{array}{l}\text { Time after diagnosis } \\
>5 \text { years }(\mathrm{n}=36)\end{array}$ \\
\hline $\begin{array}{llr}\text { Initial } & \text { DAS28 } & <3.2 \\
(\% & \text { patients } & \text { in } \\
\text { remission })(n=10)\end{array}$ & $100 \%$ & & $100 \%$ & $75.0 \%$ \\
\hline $\begin{array}{l}\text { Initial DAS28 } 3.2-5.1 \\
(\% \text { patients in } \\
\text { remission })(n=31)\end{array}$ & $75.0 \%$ & & $69.2 \%$ & $28.6 \%$ \\
\hline $\begin{array}{l}\text { Initial DAS28 } \geq 5.1 \\
(\% \text { patients in } \\
\text { remission })(n=30)\end{array}$ & $50.0 \%$ & & $50.0 \%$ & $7.1 \%$ \\
\hline
\end{tabular}

\section{Relation between the starting early of anti- TNF treatment and the dose used}

Spacing strategy was performed in $25.6 \%$ of patients: ETN (38.5\%), ADA (20.0\%) and IFX $(18.8 \%)$. The percentage of patients treated with a higher dose of IFX (according to the label dose) was considerably higher (81\%) than ADA $(12.5 \%)$ and $\operatorname{ETN}(7.7 \%)$.

No differences were observed either between anti-TNFs doses with the initial DAS28 ( $\mathrm{p}=$ 0.628 ) or in the time between diagnosis and the first anti-TNF $(p=0.670)$. Also, there was no correlation in drugs studied separately with this association.

\section{DISCUSSION}

Results suggest a better response based on DAS28 at early beginning with anti-TNFs, with a significant correlation in the time between diagnosis and the beginning of anti-TNF therapy. $85.7 \%$ of patients treated with anti-TNF during the first year since the diagnosis reached "good response" (EULAR criteria) and $71.4 \%$ were in remission at the end of the study. Initial DAS28 is related with response, as expected. $63.6 \%$ of patients treated with the first anti-TNF with a DAS28 $<3.2$ reached remission, with a gradual decreasing of the percentage when bigger the initial DAS28 is.
Currently, starting treatment with MTX is recommended. Moreover, it is known that the earlier the treatment starts the better the outcome. However, for early and aggressive RA, its combination with an anti-TNF is also recommended $(8,9)$. In the PREMIER study $(10)$ three different ways for beginning treatment were compared: MTX, ADA and MTX+ADA, and the combination therapy showed the best results for all the variables measured. In the BEST study (11), the combination of DMARDs and IFX or prednisone showed the best results in previously untreated patients with a less than two years diagnosis. A study done by the Rheumatology Spanish Society (SER) shows that the cost of the drug is $56 \%$ of the total cost of the disease (13). In Spain, the mean annual cost per patient is about 5.111€ (between $1.616 €$ and $15.345 €)(14,15)$. The data of the current study shows a better prognostic in patients treated with anti-TNF when there is a low-moderate activity of RA. However, an early beginning of BT means an increase in cost associated to drugs.

Therefore, an economic-drug analysis is warranted in order to assess whether potential improvement in quality of life due to early treatment with anti-TNFs provokes a reduction in indirect costs higher than the expense of early beginning of the treatment.

One of the disadvantages of the early treatment with anti-TNFs, besides the cost of the drug, is a higher exposure to these molecules, 
which can stimulate antibody production (16), being one of the factors that could contribute to a loss of response $(17,18)$, and therefore, a dose increase requirement (19).

Although the reasons for lack of response over time are not clear, it has been observed that an increase of the dose or a reduction of the dose interval of IFX provides additional benefits to these patients (19). Besides, this increasing in the dose results in increased cost. On the other hand, the spacing strategy is a tool which improves efficiency because it reduces the costs associated to the drug. In our study, $38.5 \%$ of patients were treated with a higher interval dose of ETN according to label doses. While on the other hand, $81.3 \%$ of patients with IFX patients use higher doses than the ones recommended. These results are similar to the ones shown in previous studies $(14,20)$. A common pattern between patients on spacing therapy has not been found. The initial DAS28 has not been associated either to the spacing therapy or the time between the diagnosis and the starting of treatment with antiTNF. However, we should take into account that these adjustments have been made randomly by the physician.

An important limitation is that certolizumab and golimumab, anti-TNFs used in RA treatment, were not studied because at the moment of inclusion marketing approvals were not yet authorized. Studies evaluating the 5 antiTNFs together ought to be done when an enough population treated with the new drugs exists. Another limitation is that the effectiveness has only been measured with the DAS28, other parameters such as clinic impression, the Health Assessment Questionnaire (HAQ), Rheumatoid Factor (RF) or anti-cyclic citrullinated peptides (anti-CCP) could have given more information to data.

In conclusion, it is suggested that the early treatment with anti-TNF can achieve a higher percentage of remissions. Therapeutic spacing is established as a strategy to improve efficiency in patients in remission, being the ETN the antiTNF most susceptible for the spacing, although a relation between the early beginning with antiTNF and the used dose was not found. However, the present data should not be generalized as they have been generated from the clinical practice of only two hospitals.

\section{CONFLICT OF INTERESTS STATEMENT}

This study was evolved as part of an educational project funded by Pfizer, although it was completely designed and carried out by the authors and was promoted by both hospitals. Authors declare not having any other tie or relationship with industry. The study results were not biased by any external influence.

\section{REFERENCES}

1. Del Rincón ID, Williams K, Stern MP, Freeman GL, Escalante A. High incidence of cardiovascular events in a rheumatoid arthritis cohort not explained by traditional cardiac risk factors. Arthritis Rheum, 2001;44(12):2737-45.

2. Abásolo L, Júdez E, Descalzo MA, GonzálezAlvaro I, Jover JA, Carmona L, on behalf of the EMECAR Study Group. Cancer in rheumatoid arthritis: occurrence, mortality, and associated factors in a South European population. Semin Arthritis Rheum, 2008;37(6):388-97.

3. Carmona L, Villaverde V, Hernandez-Garcia C, Ballina J, Gabriel R, Laffon A. The prevalence of rheumatoid arthritis in the general population of Spain. Rheumatology. 2002;41(1):88-95.

4. Blumberg SN, Fox DA. Rheumatoid arthritis: guidelines for emerging therapies. Am J Manag Care, 2001;7(6):617-626.

5. Eberhardt KB, Fex E. Functional impairment and disability in early rheumatoid arthritis-development over 5 years. J Rheumatol, 1995;22(6):1037-1042.

6. Scott DL, Pugner K, Kaarela K, Doyle DV, Woolf A, Holmes J et al. The links between joint damage and disability in rheumatoid arthritis. Rheumatology, 2000;39(2):122-132.

7. Raza K, Buckley CE, Salmon M, Buckley CD. Treating very early rheumatoid arthritis. Best Pract Res Clin Rheumatol, 2006;20(5):849-863.

8. Smolen JS, Aletaha D, Bijlsma JW, Breedveld FC, Boumpas D, Burmester G, et al. Treating rheumatoid arthritis to target: recommendations of an international task force. Ann Rheum Dis, 2010;69(4):631-7.

9. Ma MH, Kingsley GH, Scott DL. A systematic comparison of combination DMARD therapy and tumour necrosis inhibitor therapy with methotrexate in patients with early rheumatoid arthritis. Rheumatology, 2010;49(1):91-8.

10. Breedveld FC, Weisman MH, Kavanaugh AF, Cohen SB, Pavelka K, van Vollenhoven R, et al. The PREMIER study: A multicenter, randomized, double-blind clinical trial of combination therapy with adalimumab plus methotrexate versus methotrexate alone or adalimumab alone in patients with early, aggressive rheumatoid arthritis who had not had previous methotrexate treatment. Arthritis Rheum, 2006;54(1):26-37.

11. Goekoop-Ruiterman YP, de Vries-Bouwstra JK, Allaart CF, van Zeben D, Kerstens PJ, Hazes JM, et al. Clinical and radiographic outcomes of four different treatment strategies in patients with early rheumatoid arthritis (the BeSt study): A 
randomized, controlled trial. Arthritis Rheum, 2008;58(2):S126-35.

12. van Gestel AM, Haagsma CJ, van Riel PL. Validation of rheumatoid arthritis improvement criteria that include simplified joint counts. Arthritis Rheum, 1998;41(10):1845-50.

13. Carmona L, Ballina J, Gabriel R, Laffon A, on behalf of the EPISER Study Group. The burden of musculoskeletal diseases in the general population of Spain: results from a national survey. Ann Rheum Dis, 2001;60:1040-5.

14. Ruiz-Montesinos MD, Hernández-Cruz B, ArizaAriza R, Carmona L, Ballina J, Navarro-Saravia $\mathrm{F}$, on behalf of the Grupo de Estudio de Costes $\mathrm{y}$ Calidad de Vida en Artritis Reumatoide de la Sociedad Española de Reumatología. Análisis de costes en una cohorte de enfermos con artritis reumatoide atendidos en área especializada de reumatología en España. Reumatol Clin, 2005;1:193-199.

15. Rubio-Terrés C, Ordovás Baines JP, Pla Poblador R, Martínez Nieto C, Sánchez Garre MJ, Rosado Souvirón MA, et al. Use and cost of biological disease-modifying anti-rheumatic drugs in Spain (PRAXIS study). Farm Hosp, 2007;31(2):78-92.

16. Anderson PJ. Tumor necrosis factor inhibitors: clinical implications of their different immunogenicity profiles. Semin Arthritis Rheum, 2005;34(5):19-22.
17. Wolbink GJ, Vis M, Lems W, Voskuyl AE, de Groot E, Nurmohamed MT, et al. Development of antiinfliximab antibodies and relationship to clinical response in patients with rheumatoid arthritis. Arthritis Rheum, 2006;54(3):711-5.

18. Bartelds GM, Wijbrandts CA, Nurmohamed MT, Stapel S, Lems WF, Aarden L, et al. Clinical response to adalimumab: relationship to antiadalimumab antibodies and serum adalimumab concentrations in rheumatoid arthritis. Ann Rheum Dis, 2007;66(7):921-6.

19. Haraoui B, Cameron L, Ouellet M, White B. Anti-infliximab antibodies in patients with rheumatoid arthritis who require higher doses of infliximab to achieve or maintain a clinical response. J Rheumatol, 2006;33(1):31-6.

20. Moots RJ, Haraoui B, Matucci-Cerinic M, van Riel PL, Kekow J, Schaeverbeke $\mathrm{T}$, et al. Differences in biologic dose-escalation, nonbiologic and steroid intensification among three anti-TNF agents: evidence from clinical practice. Clin Exp Rheumatol, 2011;29(1):26-34. 